\title{
The relationships between asthma control, daytime sleepiness, and quality of life among children with asthma: a path analysis
}

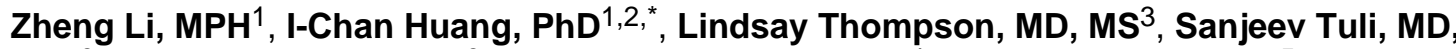 \\ Med $^{3}$, Shih-Wen Huang, MD 3 , Darren DeWalt, MD, MPH ${ }^{4}$, Dennis Revicki, $\mathrm{PhD}^{5}$, and \\ Elizabeth Shenkman, $\mathbf{P h D}^{1,2}$ \\ ${ }^{1}$ Department of Health Outcomes and Policy, College of Medicine, University of Florida, \\ Gainesville, FL \\ ${ }^{2}$ Institute for Child Health Policy, College of Medicine, University of Florida, Gainesville, FL \\ ${ }^{3}$ Department of Pediatrics, College of Medicine, University of Florida, Gainesville, FL \\ ${ }^{4}$ Department of Medicine, School of Medicine, University of North Carolina-Chapel Hill \\ ${ }^{5}$ Outcomes Research, United BioSource Corporation, Bethesda, MD
}

\begin{abstract}
Objectives-We aimed to examine the relationships between asthma control, daytime sleepiness, and asthma-specific health-related quality of life (HRQOL) among children with asthma. Path analyses were conducted to test if daytime sleepiness can mediate the effect of asthma control status on asthma-specific HRQOL.
\end{abstract}

Methods-160 dyads of asthmatic children and their parents were collected for analyses. The Asthma Control and Communication Instrument (ACCI) was used to categorize adequate and poor asthma control status. The Cleveland Adolescent Sleepiness Questionnaire (CASQ) was used to measure children's daytime sleepiness, including sleep in school, awake in school, sleep in evening, and sleep during transport. The Patient-Reported Outcomes Measurement Information System (PROMIS) Asthma Impact Scale was used to measure asthma-specific HRQOL.

Results-Poorly controlled asthma was associated with daytime sleepiness and impaired asthmaspecific HRQOL. Asthma control status was directly associated with asthma-specific HRQOL $(P<.05)$, whereas sleep in school and sleep in evening domains of daytime sleepiness significantly mediated the relationship between poor asthma control and impaired HRQOL $(P<.01)$.

Conclusions-Asthma control status was associated with pediatric asthma-specific HRQOL, and the association was significantly mediated by daytime sleepiness. Healthcare providers need to address pediatric sleep needs related to poor asthma control to reduce the impact on HRQOL.

\footnotetext{
(C) 2013 Elsevier B.V. All rights reserved.

"Corresponding author. Address: Department of Health Outcomes and Policy, and Institute for Child Health Policy, College of Medicine, University of Florida PO Box 100177, Gainesville FL 32610. Tel.: 352-265-2514; fax: 352-265-7221. ichuang@ ufl.edu (IC Huang).

Conflict of interest

All coauthors declare no conflict of interest.

Publisher's Disclaimer: This is a PDF file of an unedited manuscript that has been accepted for publication. As a service to our customers we are providing this early version of the manuscript. The manuscript will undergo copyediting, typesetting, and review of the resulting proof before it is published in its final citable form. Please note that during the production process errors may be discovered which could affect the content, and all legal disclaimers that apply to the journal pertain.
} 


\section{Keywords}

Asthma control; children; health-related quality of life; patient-reported outcomes; sleepiness; structural equation modeling

\section{Introduction}

Asthma is one of the most prevalent pediatric chronic diseases in the United States, affecting an estimated 7 million (approximately 10\%) of children in 2007 [1,2]. Although effective medication is available to treat pediatric asthma, many children are still living with persistent asthma symptoms, including shortness of breath, coughing, wheezing, nighttime awakening, and sleeping difficulties [3,4]. Underuse of oral corticosteroids and overuse of rescue medicine are important issues contributing to poorly controlled asthma [5,6]. Previous studies have shown that the prevalence of poorly controlled asthma status is various (37\%-80\%) among children with asthma, depending on different study designs, age of children, severity of asthma, and other factors [7-13]. For example, one study reported that $46 \%$ of the asthmatic children who used inhaled corticosteroids had poorly controlled asthma [13]. Numerous studies have illustrated that poor asthma control in children was associated with activity intolerance leading to impaired functional status, such as attention difficulty [14], poor sleep quality [14], poor peer relationships [15], absence from school [16], academic underperformance [16], and low asthma-specific health-related quality of life (HRQOL) [17,18].

The relationship between asthma symptoms and HRQOL is well-established. A systematic review found that asthmatic children with poor control were more likely to experience poorer HRQOL compared to those with adequate control [19]. Using the Pediatric Quality of Life Inventory to measure generic HRQOL, a study found that children with asthma had considerable impaired physical, emotional, social, and school functioning compared to that of healthy children [20]. In addition, a study using the Pediatric Asthma Quality of Life Questionnaire to measure asthma-specific HRQOL reported that HRQOL was significantly impaired in the domains of symptoms, activity limitation, and overall HRQOL among children with unstable asthma control compared to children with stable asthma control [21].

Asthmatic children are more likely to report sleep concerns than healthy children [22-24]. Airway resistance greatly increases at nighttime when people sleep, and this issue is significant for asthmatic children leading to exacerbated coughing, wheezing, and sleeping difficulties [25]. Although $25 \%$ of the general US population of children experienced nighttime sleep difficulties [26], 34\% to $40 \%$ of asthmatic children experienced nocturnal awakening $[27,28]$. Asthmatic children with poor asthma control status had more nocturnal awakening per week compared to children with adequate asthma control status (66\% vs 14\%) [29]. Children with nighttime sleep concerns had more difficulties in growth, development, and functional status, including attention difficulties, daytime sleepiness, poor school performance, missed school days [30,31], and psychologic dysfunction (i.e., anxiety, depression) [32-34]. Previous pediatric studies have separately investigated the relationships between asthma control and HRQOL [15,16,19-21], between sleep concerns and HRQOL [30,32-34] and between asthma control and sleep concerns [22-24], yet the complex mechanism among asthma control status, sleep concerns, and HRQOL has not been explored. Sleep concerns including nighttime sleep and daytime sleepiness are equally important to asthmatic children, but the majority of the studies focus on nighttime sleep rather than daytime sleepiness difficulties $[23,24,26-28,30]$. 
The purpose of our study was to examine the relationships among asthma control status, daytime sleepiness, and asthma-specific HRQOL in asthmatic children. Instead of viewing sleep concerns as a nuisance variable, we hypothesized that daytime sleepiness is an important factor to mediate the relationship between asthma control status and HRQOL. Specifically we used path analysis methodology to quantify the direct and indirect effects of asthma control on asthma-specific HRQOL through the mechanism of daytime sleepiness [35].

\section{Methods}

\subsection{Population and data collection}

This cross-sectional study used data collected from children who were previously diagnosed with asthma between the ages of 8 and 17 years and their parents. Exclusion criteria were parents and children who had any concurrent medical or psychiatric conditions that may have affected the completion of the survey, children who had asthma-like symptoms but were not diagnosed as having asthma, or parents and children who were not able to read and speak English. After the University of Florida's institutional review board approved the protocol, we recruited 160 asthmatic children and their parents between June 2010 and August 2011 who visited the University of Florida Pediatric Primary Care at Gerold L. Schiebler Children's Medical Services Center and Tower Square, the Pediatric After Hours Clinic, the Pediatric Allergy Clinic, or the Pediatric Pulmonary Clinic. During the scheduled clinical visit, children filled out the questionnaires measuring daytime sleepiness and asthma-specific HRQOL, and parents filled out the questionnaire measuring asthma control status and sociodemographic characteristics.

\subsection{Measurement and instruments}

Three well-validated instruments, Asthma Control and Communication Instrument (ACCI) [36], Cleveland Adolescent Sleepiness Questionnaire (CASQ) [37], and National Institutes of Health Pediatric Patient-Reported Outcomes Measurement Information System (PROMIS) were used to measure asthma control status [38], daytime sleepiness, and asthma-specific HRQOL, respectively.

The ACCI is comprised of 12 items measuring 5 domains of asthma status, including perception of asthma concern ( 1 item), asthma control (5 items), direction of symptoms (1 item), short-term care (3 items), and adherence to asthmatic medication ( 1 item). In addition, one open-ended question was used to collect the family's needs for assistance with asthma management [36]. The ACCI has demonstrated good psychometric properties, including internal consistency reliability, convergent and discriminatory validity, and known-group validity [36]. In compliance with the National Asthma Education Prevention Program (NAEPP) Expert Panel Report 3 (EPR-3) for measuring asthma control status, 5 items (symptoms, nighttime awakening, the use of short-acting $\beta 2$ agonists for quick relief of symptoms, limitations to normal activities, and asthma attack frequency) were included in this instrument. For an individual patient, we classified the answer from each item into wellcontrolled, not well-controlled, and very poorly controlled. Consistent with the NAEPP EPR-3, the overall control status of an individual patient is determined by the most severe response among the 5 items [39]. That is, each patient was assigned to the adequate control group (in line with EPR-3's well-controlled) if he or she endorsed all of the 5 items as wellcontrolled; otherwise, a patient was assigned to the poor control group (in line with EPR-3's not well-controlled and very poorly controlled) [36,39].

The CASQ is comprised of 16 items measuring excessive daytime sleepiness and alertness in adolescents, including 4 domains of sleep in school, awake in school, sleep in evening, and sleep during transport [37]. In contrast with other self-reported sleep measures for 
pediatric populations, the CASQ focuses on daytime sleepiness symptoms and does not include any questions measuring nighttime sleep concerns or symptoms of sleeping difficulties. The CASQ has demonstrated acceptable internal consistency reliability with a Cronbach a of 0.89 and a satisfactory convergent and discriminatory validity by comparing the CASQ scores to the scores of 2 legacy daytime sleepiness measures, the Pediatric Daytime Sleepiness Scale and School Sleep Habits Survey [37]. Because the CASQ measures children's sleepiness issues during and after school, it captures the full spectrum of children's daytime activities relevant to sleepiness. Our study specifically examined which domains of daytime sleepiness were significantly related to asthma control and asthmarelated HRQOL. The response categories for each item were never, rarely, sometimes, often, and almost every day. The domain score was calculated by summing individual item scores within the domain, with higher scores indicating more daytime sleepiness concerns.

The National Institutes of Health's PROMIS pediatric scales were designed to measure important domains of patient-reported outcomes, including physical function, depression, anxiety, fatigue, mobility, pain, peer relationship, and asthma impact [38]. Our study used the asthma impact domain ( 8 items) to measure asthma-specific HRQOL in children. The PROMIS Asthma Impact Scale has demonstrated good construct validity based on item response theory to assess the unidimensionality and the satisfactory convergent and discriminatory validity by comparing its scale score to the Pediatric Quality of Life Inventory asthma symptoms scale score $[38,40]$. The response categories for each item are never, almost never, sometimes, often and almost always. The domain score was calculated by item response theory, with higher scores indicating greater impairment in HRQOL.

\subsection{Statistical analysis}

Descriptive analyses were performed to investigate the distributions of demographic characteristics among 160 dyadic participants based on mean and standard deviation (SD) of child's and parent's age, child's gender, race or ethnicity, presence of comorbid conditions (e.g., high blood pressure, attention deficit hyperactivity disorder, or other learning disabilities), asthma control status, and parent's education level, race or ethnicity, and family incomes. In addition, mean, median, and SD, and floor and ceiling effects were reported for individual domains of the CASQ and the PROMIS instruments. We defined ceiling and floor effects as the percentage of the participants who reported the highest and lowest scores for each domain, respectively.

Regression analyses and $t$ tests were performed to examine the bivariate and multivariate relationships among asthma control, daytime sleepiness, and asthma-specific HRQOL. Six linear regression models were conducted using asthma-specific HRQOL as the outcome variable. Different independent variables were included in different regression models, including asthma control in model 1, sleep in school domain of the CASQ in model 2, awake in school domain of the CASQ in model 3, sleep in evening domain of the CASQ in model 4, sleep during transportation domain of the CASQ in model 5, and all 4 domains of the CASQ in model 6. Child's age and gender as well as parental age, race or ethnicity, education background, and family income were adjusted in each regression model.

Finally, path analyses were performed to examine the direct effect of asthma control on asthma-specific HRQOL, and the indirect effect of asthma control status on asthma-specific HRQOL through the 4 domains of daytime sleepiness as mediators. We used structural equation modeling (SEM) to quantify the direct and indirect effects of asthma control on asthma-specific HRQOL. The unique feature of SEM methodology is the ability to simultaneously estimate the regression coefficients for a hypothesized complex pathway between the variables of interest. In SEM we assumed that the constructs of the 4daytime sleepiness domains and asthma-specific HRQOL were latent and that they would be 
estimated by the indicators (i.e., items) of the instruments. Two SEMs were performed consisting of a simple model examining the relationship between asthma control and asthma-specific HRQOL and a full model examining the relationships among asthma control, daytime sleepiness, and asthma-specific HRQOL. The full SEM tested all pathways among asthma control, all domains of daytime sleepiness, and asthma-specific HRQOL. We used the root mean square error of approximation (RMSEA) and comparative fit index (CFI) to indicate the adequacy of the model fit. The possible values of RMSEA and CFI were between 0 and 1 , and the values of RMSEA $<0.08$ and CFI $>0.9$ were considered as a satisfied model fit $[41,42]$.

In our study, Mplus 6 (Muthen and Muthen, Los Angeles, CA) was used for path analyses, and SAS 9.2 (SAS Institute Inc., Cary, NC) was used for the rest of the analyses.

\section{Results}

\subsection{Participant characteristics}

Table 1 shows the participant characteristics. For children $(\mathrm{N}=160)$, the mean age was 11.6 years (SD, 2.4); the majority were boys (59.4\%) and of black descent (55.6\%). For parents, the mean age was 40.1 years (SD, 9.6), and the majority were of black descent $(54.4 \%)$ and had educational background of some college or an Associate degree (41.9\%) or above. Approximately $68 \%$ of children reported at least one comorbid conditions, and $51.9 \%$ of children had poor asthma control status.

\subsection{Measurement of daytime sleepiness and asthma-specific HRQOL}

Table 2 shows the domain scores of daytime sleepiness and asthma-specific HRQOL. All domain scores of daytime sleepiness were slightly skewed to better outcomes; however, the scores in asthma-specific HRQOL were slightly skewed to worse outcomes. Ceiling effects were not significant ( $<10 \%$ of the participants) in all domains; however, the floor effects were significant ( $>30 \%$ of the participants) in the sleep in school domain.

\subsection{Bivariate associations between asthma control, daytime sleepiness, and asthma- specific HRQOL}

Table 3 shows the bivariate associations between asthma control on the 4 domains of daytime sleepiness and asthma-specific HRQOL, respectively, based on the $t$ tests. In general children with poor asthma control status were significantly associated with greater daytime sleepiness in all domains $(P<.01)$ (except the awake in school domain), and poorer asthma-specific HRQOL $(P<.01)$ than those with adequate control status.

\subsection{Multivariate association between asthma control, daytime sleepiness, and asthma- specific HRQOL}

Table 4 shows the relationships between asthma control, daytime sleepiness, and asthmaspecific HRQOL based on regression analyses. Model 1 revealed that poor asthma control status was significantly associated with impaired asthma-specific HRQOL after adjusting for covariates $(P<.001)$. Models 2, 3, 4, and 5 showed 3 domains of daytime sleepiness (sleep in school, sleep in evening, and sleep during transport) were significantly associated with impaired HRQOL $(P<.01)$. With the inclusion of all 4 daytime sleepiness domains, model 6 showed that only sleep in school and sleep in evening domains were significantly associated with impaired asthma-specific HRQOL $(P<.01)$. This finding suggests that the significant association of sleep during transport with asthma-specific HRQOL was explained by the domains of sleep in school and sleep in evening. 


\subsection{Direct and indirect effects of asthma control on asthma-specific HRQOL}

Fig. 1A shows the direct effect of asthma control on asthma-specific HRQOL without including daytime sleepiness in the SEM analysis. The estimated magnitude of direct effect was $0.425(P<.01)$, and the model fit was marginally satisfied with RMSEA of 0.08 and unsatisfied with CFI of 0.865 .

Fig. 1B shows the mediating effects of daytime sleepiness on the relationship between asthma control and asthma-specific HRQOL based on the full SEM path analytic model. The model fit was satisfied with RMSEA of 0.069 and CFI of 0.902. However, the direct effect of asthma control on asthma-specific HRQOL was decreased from $0.425(P<.01)$ (Fig. 1A) to $0.242(P<.01)$ (Fig. 1B). Although poor asthma control status was significantly associated with impaired asthma-specific HRQOL, the relationships were partially explained by the mediating effects of daytime sleepiness. Approximately $43 \%$ of the total variance in the asthma control-HRQOL association was explained by the indirect effects of daytime sleepiness. This finding implies that daytime sleepiness plays an important role in mediating the relationship between asthma control status and asthma-specific HRQOL.

Specifically, 2 significant pathways were identified suggesting the indirect effects of asthma control on asthma-specific HRQOL through 2 daytime sleepiness domains. The first pathway was asthma control status on asthma-specific HRQOL through sleep in school (magnitude, $0.067 ; P<.05$ ). The second pathway was asthma control status on asthmaspecific HRQOL through sleep in evening (magnitude, $0.084 ; P<.05$ ).

\section{Discussion}

To our knowledge, our study is among the first to articulate the effect of daytime sleepiness on the relationship between asthma control status and asthma-specific HRQOL in asthmatic children. We found poorly controlled asthma was associated with daytime sleepiness and impaired asthma-specific HRQOL. However, we extend the literature and suggest that, although poor asthma control status was directly and significantly associated with impaired asthma-specific HRQOL, 2 daytime sleepiness domains (sleep in school and sleep in evening) significantly mediated the aforementioned direct relationship. These 2 sleepiness domains cover the important daily activity difficulties that asthmatic children face yet rarely are discussed in the literature.

The NAEPP EPR-3 guidelines emphasize the importance of monitoring and managing asthma control status [39]. Poor asthma control in which children did not adhere to effective treatment plans and endured acute asthma attacks and symptom exacerbation is related to significant HRQOL impairment [43]. Indeed, it appears that a substantial part of the relationship between asthma control and HRQOL is a consequence of sleep concerns. This insight emphasizes the importance of assessing nighttime symptoms and daytime sleepiness by clinicians as an important element of managing pediatric asthma.

Conceptually sleepiness difficulties during daytime might be indicative of sleep difficulties or poor nighttime sleep quality due to asthma symptoms. We partially support this hypothesis because the ACCI includes one item (How many nights did asthma wake him/her up?) to measure nocturnal awakening and nighttime sleep disturbance [44], and we found that children with more nocturnal sleep difficulties experienced more daytime sleepiness compared to children with less nocturnal sleep difficulties. For children who experience more nighttime sleep difficulties together with sleepiness during and after school, alertness and concentration in class will be suboptimal, and ultimately their physical, mental, and social functioning will be affected. 
To help identify sleep difficulties in children with poor health conditions such as asthma, it is critical to use conceptually sound and psychometrically tools to appropriately measure nighttime and daytime sleepiness-related difficulties. Although electrophysiologic techniques such as electroencephalography and polysomnography are regarded as the gold standard to measure sleep quality, the use of self-report instruments provides supplementary information. Buysse et al [45] developed PROMIS sleep disturbance and sleep-related impairments item banks which could potentially be used to assess general sleep difficulties in clinical settings. Unfortunately, the sleep-related item banks were not designed for children and youth. Other instruments such as the Pittsburgh Sleep Quality Index [46] and Insomnia Severity Index [47] are restricted to a narrow scope of sleep difficulties and merely are designed for adults. The Pittsburgh Sleep Quality Index identifies 7 important domains, including sleep latency, sleep duration, sleep disturbances, and subjective sleep quality [46]. The Insomnia Severity Index focuses on difficulties with sleep onset, with sleep maintenance, with early awakening, and satisfaction with sleep pattern [47].

Identifying appropriate therapeutic strategies to address sleep difficulties in asthmatic children is neglected in most clinical settings due in part to the complex mechanisms or unknown effects. Appropriate use of controller medication is the one of the resolutions for sleep difficulty among asthmatic children [48]. Some children may benefit from environmental allergen reduction such as exposure to dust mites in bed [25]. A clinical trial showed that continuous positive airway pressure (CPAP) might improve sleep apnea and daytime sleepiness [49]. Unfortunately, this study was conducted in adults rather than in pediatric populations. Interventions based on physiologic, psychologic, and behavioral perspectives [50] might be useful to address nighttime sleep difficulties and daytime sleepiness issues faced by children who frequently have poor asthma control status.

Some limitations should be noted in the interpretations of the findings. First our participants were recruited from a single academic institution where their characteristics may be different from the general population. Second our study focused on the pathways in which poorly controlled asthma influenced HRQOL through poor daytime sleepiness. We did not take into account and test other potential mediators such as allergic rhinitis and exerciseinduced bronchoconstriction [51] in the path analysis. Daytime sleepiness only explained part of indirect effect (43\%) between asthma control and asthma-specific HRQOL, and we believe these aforementioned factors might have contributed to the pathway. Third we decided a priori that the parental report rather than the child's report should be used for asthma control assessment. The rationale is that some items measuring asthma control are related to medication use, and we believe parents generally understand the types of medication more appropriately than adolescents. As a caregiver in the family, a parent also understands their child's asthma symptoms. In contrast, adolescents more appropriately perceive their HRQOL and daytime sleepiness difficulties than parents. Previous studies have shown that both parents and children were likely to overreport adherence to asthma medication than the use of objective measures such as asthma inhaler canister weight checks and electronic canister measures [52,53]. Interestingly, medication use reported by parents and children was not significantly different [52,53]. Because few studies have investigated the discrepancy in asthma control status between parent proxy report and adolescent selfreport, further studies are needed to better understand the validity of different asthma control measures. Fourth we were only able to collect spirometry data (forced expiratory volume in 1 second and forced vital capacity) from $5 \%$ of the participants. Spirometry measurement provides important information regarding a patient's asthma status, especially lung function. However, collecting spirometry data from pediatric patients is challenging. A recent review article emphasized the importance of collecting spirometry data but recognized that few studies have used both spirometry and patient-reported outcomes information to measure asthma control status due to the practical challenges [54]. Finally the pathway of asthma- 
control daytime sleepiness-HRQOL was based on a cross-sectional design, which does not provide information on causation. A longitudinal study design with multiple end point measurements is needed to establish the temporal sequence and confirm the causal relationship. In addition, the use of a longitudinal study design would capture asthma exacerbation or deterioration of asthma control status and answer whether or not the change of asthma control status is associated with daytime sleepiness and HRQOL. Although we did not specifically collect information on asthma exacerbation or deterioration of asthma control status, the ACCI used in our study did include one item measuring the current use of rescuer medication (i.e., short-acting $\beta 2$ agonists and oral corticosteroid burst) which is related to asthma exacerbation. Our additional analysis based on this single item of rescue medication also found the rescue medication use was significantly associated with the excess daytime sleepiness.

In conclusion, our study established the linkage among poorly controlled asthma, daytime sleepiness, and impaired asthma-specific HRQOL in asthmatic children. Poor asthma control status was associated with impaired asthma-specific HRQOL, and this association was significantly mediated by daytime sleepiness difficulties. Two daytime sleepiness concerns (sleep in school and sleep in evening) significantly mediated the relationship of asthma control with asthma-specific HRQOL. Clinicians are encouraged to screen and manage daytime sleepiness as an avenue to improve HRQOL among children with poorly controlled asthma.

\section{Acknowledgments}

The authors thank Kathleen Ryan, MD, and Elizabeth LeFave, ARNP, for screening patient eligibility, and Tiffany Brown, RN, Heidi Saliba, BA, Camille Jackson, MPH, and Mary Anderson, BS, for assisting in data collection.

Funding sources

This work was supported in part by the National Institutes of Health K23 HD057146-01 (IH) and U01 AR052181-06 (LT, DD, ES, and IH).

\section{References}

1. Akinbami LJ, Moorman JE, Bailey C, Zahran HS, King M, Johnson CA, et al. Trends in asthma prevalence, health care use, and mortality in the united states, 2001-2010. NCHS Data Brief. 2012; (94):1-8. [PubMed: 22617340]

2. Bloom B, Cohen RA, Freeman G. Summary health statistics for U.S. children: National Health Interview Survey, 2010. Vital Health Stat 10. 2011; (250):1-80. [PubMed: 22338334]

3. Ronchetti R, Villa MP, Matricardi PM, La Grutta S, Barreto M, Pagani J, et al. Association of asthma with extra-respiratory symptoms in schoolchildren: two cross-sectional studies 6 years apart. Pediatr Allergy Immunol. 2002; 13:113-8. [PubMed: 12000483]

4. Decker K, Meyer K, Littlefield D, Thompson WD. Similar asthma prevalence estimates obtained from preadolescent and parent survey responses. J Clin Epidemiol. 2008; 61:611-6. [PubMed: 18471666]

5. Akinbami LJ, Moorman JE, Garbe PL, Sondik EJ. Status of childhood asthma in the United States, 1980-2007. Pediatrics. 2009; 123(suppl 3):S131-45. [PubMed: 19221156]

6. Martinez FD, Chinchilli VM, Morgan WJ, Boehmer SJ, Lemanske RF Jr, Mauger DT, et al. Use of beclomethasone dipropionate as rescue treatment for children with mild persistent asthma (TREXA): a randomised, double-blind, placebo-controlled trial. Lancet. 2011; 377:650-7. [PubMed: 21324520]

7. Carroll WD, Wildhaber J, Brand PL. Parent misperception of control in childhood/adolescent asthma: The room to breathe survey. Eur Respir J. 2012; 39:90-6. [PubMed: 21700607]

8. Liu AH, Zeiger RS, Sorkness CA, Ostrom NK, Chipps BE, Rosa K, et al. The Childhood Asthma Control Test: retrospective determination and clinical validation of a cut point to identify children 
with very poorly controlled asthma. J Allergy Clin Immunol. 2010; 126:267-73. 273. e1. [PubMed: 20624640]

9. Smith LA, Bokhour B, Hohman KH, Miroshnik I, Kleinman KP, Cohn E, et al. Modifiable risk factors for suboptimal control and controller medication underuse among children with asthma. Pediatrics. 2008; 122:760-9. [PubMed: 18829799]

10. Hammer SC, Robroeks CM, van Rij C, Heynens J, Droog R, Jobsis Q, et al. Actual asthma control in a paediatric outpatient clinic population: do patients perceive their actual level of control? Pediatr Allergy Immunol. 2008; 19:626-33. [PubMed: 18221469]

11. Halterman JS, Auinger P, Conn KM, Lynch K, Yoos HL, Szilagyi PG. Inadequate therapy and poor symptom control among children with asthma: findings from a multistate sample. Ambul Pediatr. 2007; 7:153-9. [PubMed: 17368410]

12. Lozano P, Finkelstein JA, Hecht J, Shulruff R, Weiss KB. Asthma medication use and disease burden in children in a primary care population. Arch Pediatr Adolesc Med. 2003; 157:81-8. [PubMed: 12517200]

13. Koster ES, Raaijmakers JA, Vijverberg SJ, Koenderman L, Postma DS, Koppelman GH, et al. Limited agreement between current and long-term asthma control in children: the PACMAN cohort study. Pediatr Allergy Immunol. 2011; 22:776-83. [PubMed: 21749459]

14. Kieckhefer GM, Lentz MJ, Tsai SY, Ward TM. Parent-child agreement in report of nighttime respiratory symptoms and sleep disruptions and quality. J Pediatr Health Care. 2009; 23:315-26. [PubMed: 19720267]

15. King MT, Kenny PM, Marks GB. Measures of asthma control and quality of life: longitudinal data provide practical insights into their relative usefulness in different research contexts. Qual Life Res. 2009; 18:301-12. [PubMed: 19225906]

16. Taras H, Potts-Datema W. Childhood asthma and student performance at school. J Sch Health. 2005; 75:296-312. [PubMed: 16179080]

17. Turner S, Eastwood P, Cook A, Jenkins S. Improvements in symptoms and quality of life following exercise training in older adults with moderate/severe persistent asthma. Respiration. 2011; 81:302-10. [PubMed: 20501982]

18. Jankowska EA, Wegrzynowska K, Superlak M, Nowakowska K, Lazorczyk M, Biel B, et al. The 12-week progressive quadriceps resistance training improves muscle strength, exercise capacity and quality of life in patients with stable chronic heart failure. Int J Cardiol. 2008; 130:36-43. [PubMed: 18054809]

19. Everhart RS, Fiese BH. Asthma severity and child quality of life in pediatric asthma: a systematic review. Patient Educ Couns. 2009; 75:162-8. [PubMed: 19036553]

20. Seid M, Limbers CA, Driscoll KA, Opipari-Arrigan LA, Gelhard LR, Varni JW. Reliability, validity, and responsiveness of the pediatric quality of life inventory (PedsQL) generic core scales and asthma symptoms scale in vulnerable children with asthma. J Asthma. 2010; 47:170-7. [PubMed: 20170325]

21. Juniper EF, Guyatt GH, Feeny DH, Ferrie PJ, Griffith LE, Townsend M. Measuring quality of life in children with asthma. Qual Life Res. 1996; 5:35-46. [PubMed: 8901365]

22. Chugh IM, Khanna P, Shah A. Nocturnal symptoms and sleep disturbances in clinically stable asthmatic children. Asian Pac J Allergy Immunol. 2006; 24:135-42. [PubMed: 17136879]

23. Krouse HJ, Yarandi H, McIntosh J, Cowen C, Selim V. Assessing sleep quality and daytime wakefulness in asthma using wrist actigraphy. J Asthma. 2008; 45:389-95. [PubMed: 18569232]

24. Stores G, Ellis AJ, Wiggs L, Crawford C, Thomson A. Sleep and psychological disturbance in nocturnal asthma. Arch Dis Child. 1998; 78:413-9. [PubMed: 9659086]

25. Greenberg H, Cohen RI. Nocturnal asthma. Curr Opin Pulm Med. 2012; 18:57-62. [PubMed: 22045347]

26. Kieckhefer GM, Ward TM, Tsai SY, Lentz MJ. Nighttime sleep and daytime nap patterns in school age children with and without asthma. J Dev Behav Pediatr. 2008; 29:338-44. [PubMed: 18714207]

27. Diette GB, Markson L, Skinner EA, Nguyen TT, Algatt-Bergstrom P, Wu AW. Nocturnal asthma in children affects school attendance, school performance, and parents' work attendance. Arch Pediatr Adolesc Med. 2000; 154:923-8. [PubMed: 10980797] 
28. Strunk RC, Sternberg AL, Bacharier LB, Szefler SJ. Nocturnal awakening caused by asthma in children with mild-to-moderate asthma in the childhood asthma management program. J Allergy Clin Immunol. 2002; 110:395-403. [PubMed: 12209085]

29. Dean BB, Calimlim BC, Sacco P, Aguilar D, Maykut R, Tinkelman D. Uncontrolled asthma among children: impairment in social functioning and sleep. J Asthma. 2010; 47:539-44. [PubMed: 20536279]

30. Fitzpatrick MF, Engleman H, Whyte KF, Deary IJ, Shapiro CM, Douglas NJ. Morbidity in nocturnal asthma: sleep quality and daytime cognitive performance. Thorax. 1991; 46:569-73. [PubMed: 1926025]

31. Okelo SO, Wu AW, Krishnan JA, Rand CS, Skinner EA, Diette GB. Emotional quality-of-life and outcomes in adolescents with asthma. J Pediatr. 2004; 145:523-9. [PubMed: 15480379]

32. Rosen CL, Palermo TM, Larkin EK, Redline S. Health-related quality of life and sleep-disordered breathing in children. Sleep. 2002; 25:657-66. [PubMed: 12224844]

33. Fagnano M, van Wijngaarden E, Connolly HV, Carno MA, Forbes-Jones E, Halterman JS. Sleepdisordered breathing and behaviors of inner-city children with asthma. Pediatrics. 2009; 124:21825. [PubMed: 19564303]

34. Moore M, Kirchner HL, Drotar D, Johnson N, Rosen C, Ancoli-Israel S, et al. Relationships among sleepiness, sleep time, and psychological functioning in adolescents. J Pediatr Psychol. 2009; 34:1175-83. [PubMed: 19494088]

35. Edwards JR, Lambert LS. Methods for integrating moderation and mediation: a general analytical framework using moderated path analysis. Psychol Methods. 2007; 12:1-22. [PubMed: 17402809]

36. Patino CM, Okelo SO, Rand CS, Riekert KA, Krishnan JA, Thompson K, et al. The Asthma Control and Communication Instrument: a clinical tool developed for ethnically diverse populations. J Allergy Clin Immunol. 2008; 122:936-43. e6. [PubMed: 18848721]

37. Spilsbury JC, Drotar D, Rosen CL, Redline S. The Cleveland adolescent sleepiness questionnaire: a new measure to assess excessive daytime sleepiness in adolescents. J Clin Sleep Med. 2007; 3:603-12. [PubMed: 17993042]

38. Yeatts KB, Stucky B, Thissen D, Irwin D, Varni JW, DeWitt EM, et al. Construction of the Pediatric Asthma Impact Scale (PAIS) for the Patient-Reported Outcomes Measurement Information System (PROMIS). J Asthma. 2010; 47:295-302. [PubMed: 20394514]

39. National Asthma Education and Prevention Program. Expert panel report 3 (EPR-3): Guidelines for the Diagnosis and Management of Asthma-Summary Report 2007. J Allergy Clin Immunol. 2007; 120(suppl 5):S94-138. [PubMed: 17983880]

40. Thissen D, Varni JW, Stucky BD, Liu Y, Irwin DE, Dewalt DA. Using the PedsQL ${ }^{\mathrm{TM}} 3.0$ asthma module to obtain scores comparable with those of the PROMIS pediatric asthma impact scale (PAIS). Qual Life Res. 2011; 20:1497-505. [PubMed: 21384264]

41. Bentler PM. On the fit of models to covariances and methodology to the bulletin. Psychol Bull. 1992; 112:400-4. [PubMed: 1438635]

42. MacCallum RC, Browne MW, Sugawara HM. Power analysis and determination of sample size for covariance structure modeling. Psychol Methods. 1996; 1:130-49.

43. Ekici A, Ekici M, Kurtipek E, Keles H, Kara T, Tunckol M, et al. Association of asthma-related symptoms with snoring and apnea and effect on health-related quality of life. Chest. 2005; 128:3358-63. [PubMed: 16304284]

44. Fagnano M, Bayer AL, Isensee CA, Hernandez T, Halterman JS. Nocturnal asthma symptoms and poor sleep quality among urban school children with asthma. Acad Pediatr. 2011; 11:493-9. [PubMed: 21816697]

45. Buysse DJ, Yu L, Moul DE, Germain A, Stover A, Dodds NE, et al. Development and validation of patient-reported outcome measures for sleep disturbance and sleep-related impairments. Sleep. 2010; 33:781-92. [PubMed: 20550019]

46. Buysse DJ, Reynolds CF 3rd, Monk TH, Berman SR, Kupfer DJ. The Pittsburgh Sleep Quality Index: a new instrument for psychiatric practice and research. Psychiatry Res. 1989; 28:193-213. [PubMed: 2748771]

47. Bastien CH, Vallieres A, Morin CM. Validation of the Insomnia Severity Index as an outcome measure for insomnia research. Sleep Med. 2001; 2:297-307. [PubMed: 11438246] 
48. Garrison MM, Lozano P, Christakis DA. Controller medication use and sleep problems in pediatric asthma: a longitudinal case-crossover analysis. Arch Pediatr Adolesc Med. 2011; 165:826-30. [PubMed: 21893649]

49. Weaver TE, Mancini C, Maislin G, Cater J, Staley B, Landis JR, et al. Continuous positive airway pressure treatment of sleepy patients with milder obstructive sleep apnea: results of the CPAP Apnea Trial North American Program (CATNAP) randomized clinical trial. Am J Respir Crit Care Med. 2012; 186:677-83. [PubMed: 22837377]

50. Yang CM, Liao YS, Lin CM, Chou SL, Wang EN. Psychological and behavioral factors in patients with comorbid obstructive sleep apnea and insomnia. J Psychosom Res. 2011; 70:355-61. [PubMed: 21414455]

51. Hallstrand TS, Curtis JR, Aitken ML, Sullivan SD. Quality of life in adolescents with mild asthma. Pediatr Pulmonol. 2003; 36:536-43. [PubMed: 14618647]

52. Bender B, Wamboldt FS, O'Connor SL, Rand C, Szefler S, Milgrom H, et al. Measurement of children's asthma medication adherence by self report, mother report, canister weight, and Doser CT. Ann Allergy Asthma Immunol. 2000; 85:416-21. [PubMed: 11101187]

53. Bender BG, Bartlett SJ, Rand CS, Turner C, Wamboldt FS, Zhang L. Impact of interview mode on accuracy of child and parent report of adherence with asthma-controller medication. Pediatrics. 2007; 120:e471-7. [PubMed: 17698578]

54. Cloutier MM, Schatz M, Castro M, Clark N, Kelly HW, Mangione-Smith R, et al. Asthma outcomes: composite scores of asthma control. J Allergy Clin Immunol. 2012; 129(suppl 3):S2433. [PubMed: 22386507] 

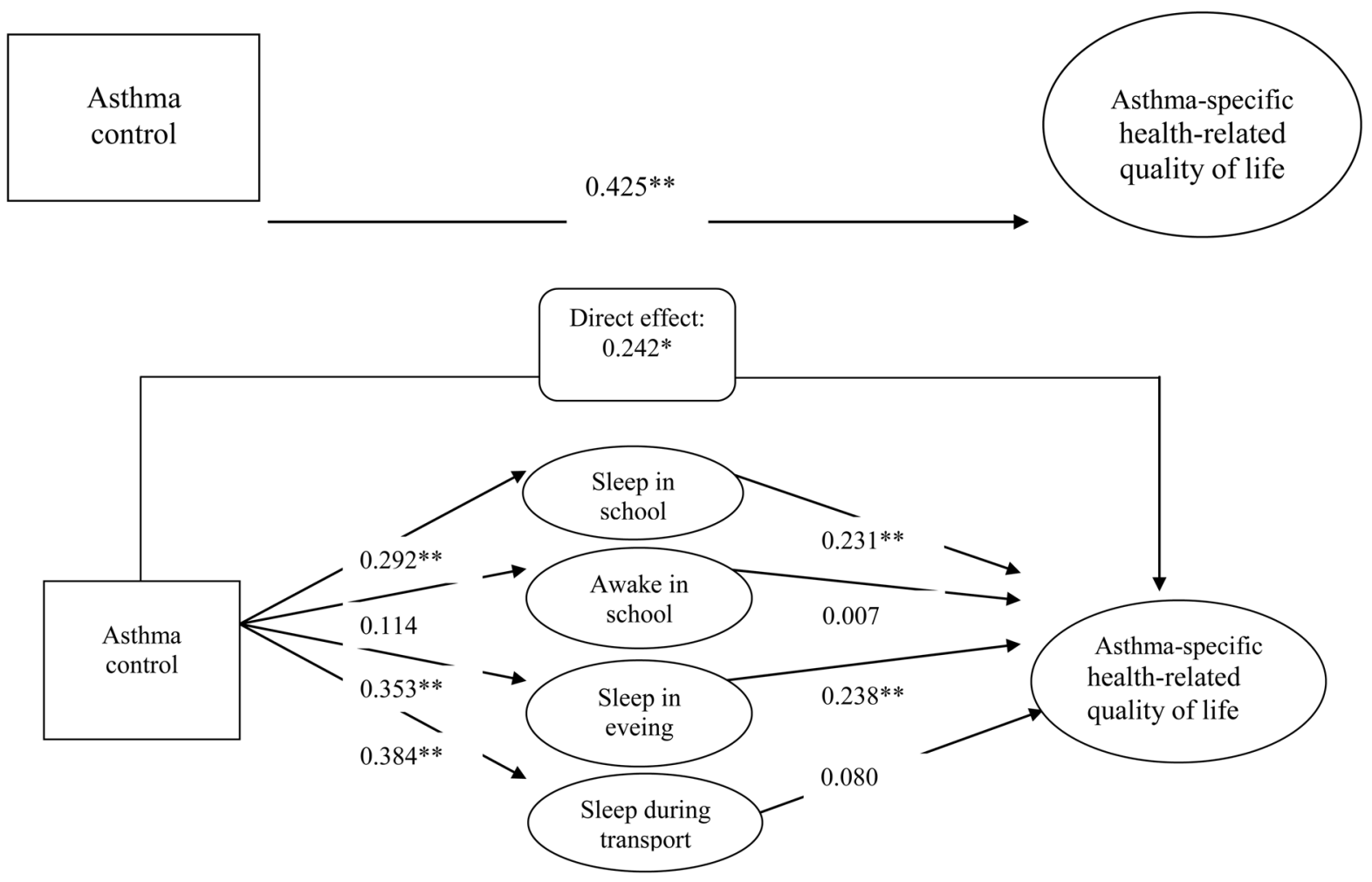

Fig. 1.

Fig. 1 (A and B)

Direct effects of asthma control on asthma-specific health-related quality of life (A).

$* P<.05$; ** $P<.01$; *** $P<.001$.

Comparative fit index, 0.865 .

Root mean square error of approximation, 0.080 .

Squares indicate observed constructs.

Ellipses indicate latent constructs.

Mediating effects of daytime sleepiness on the relationships of asthma control and asthmaspecific health-related quality of life (B).

Indirect effect (asthma control on asthma-specific health-related quality of life (HRQoL) through sleep in school), $0.067^{*}$.

Indirect effect (asthma control on asthma-specific HRQoL through awake in school), 0.001.

Indirect effect (asthma control on asthma-specific HRQoL through sleep in evening),

$0.084^{*}$.

Indirect effect (asthma control on asthma-specific HRQoL through sleep during transport), 0.031 .

Total effects (direct plus indirect effects): $0.425^{* * *}$.

$* P<.05 ; * * P<.01 ; * * * P<.001$.

Comparative fit index, 0.902 .

Root mean square error of approximation, 0.069 .

Squares indicate observed constructs.

Ellipses indicate latent constructs. 


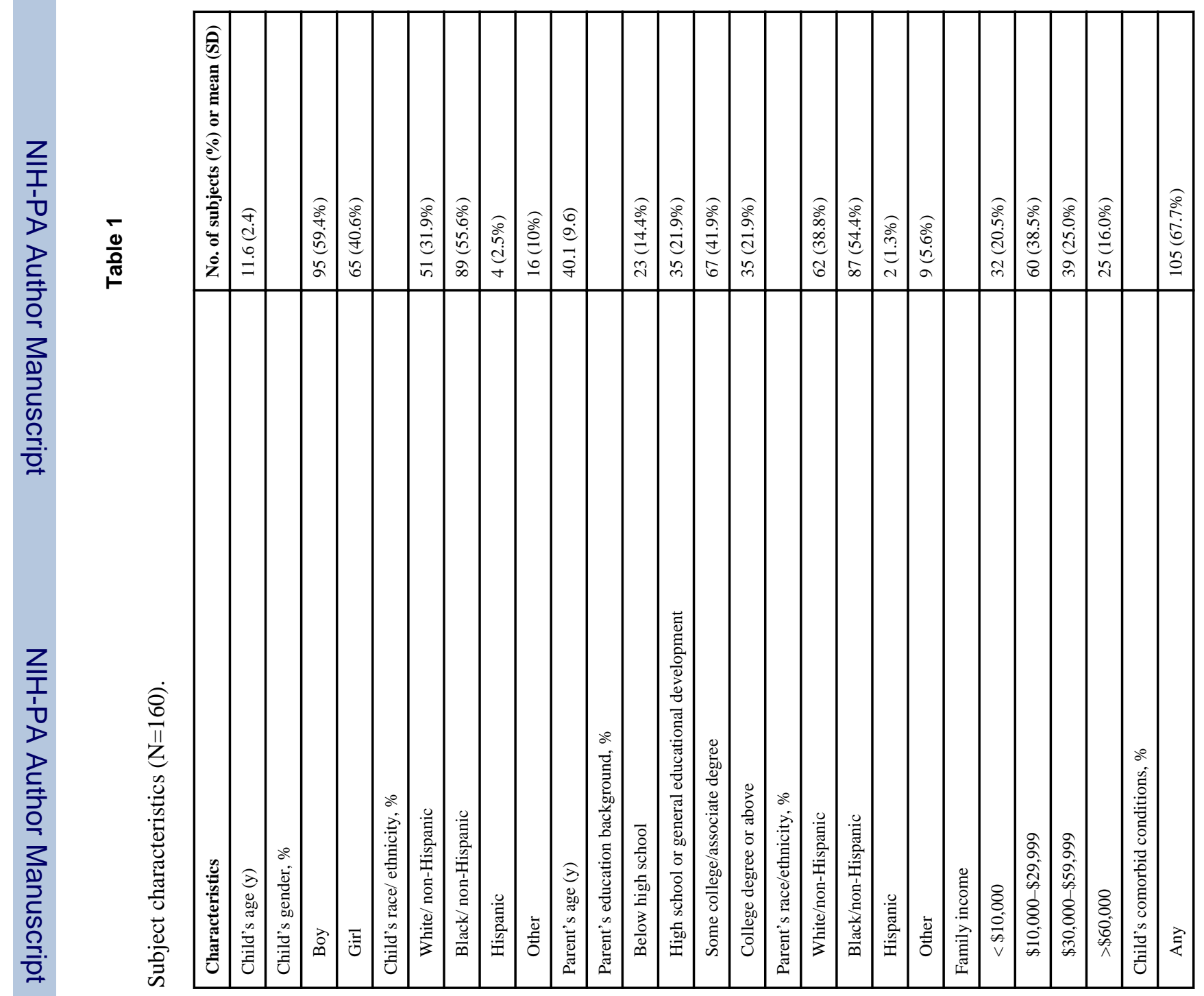




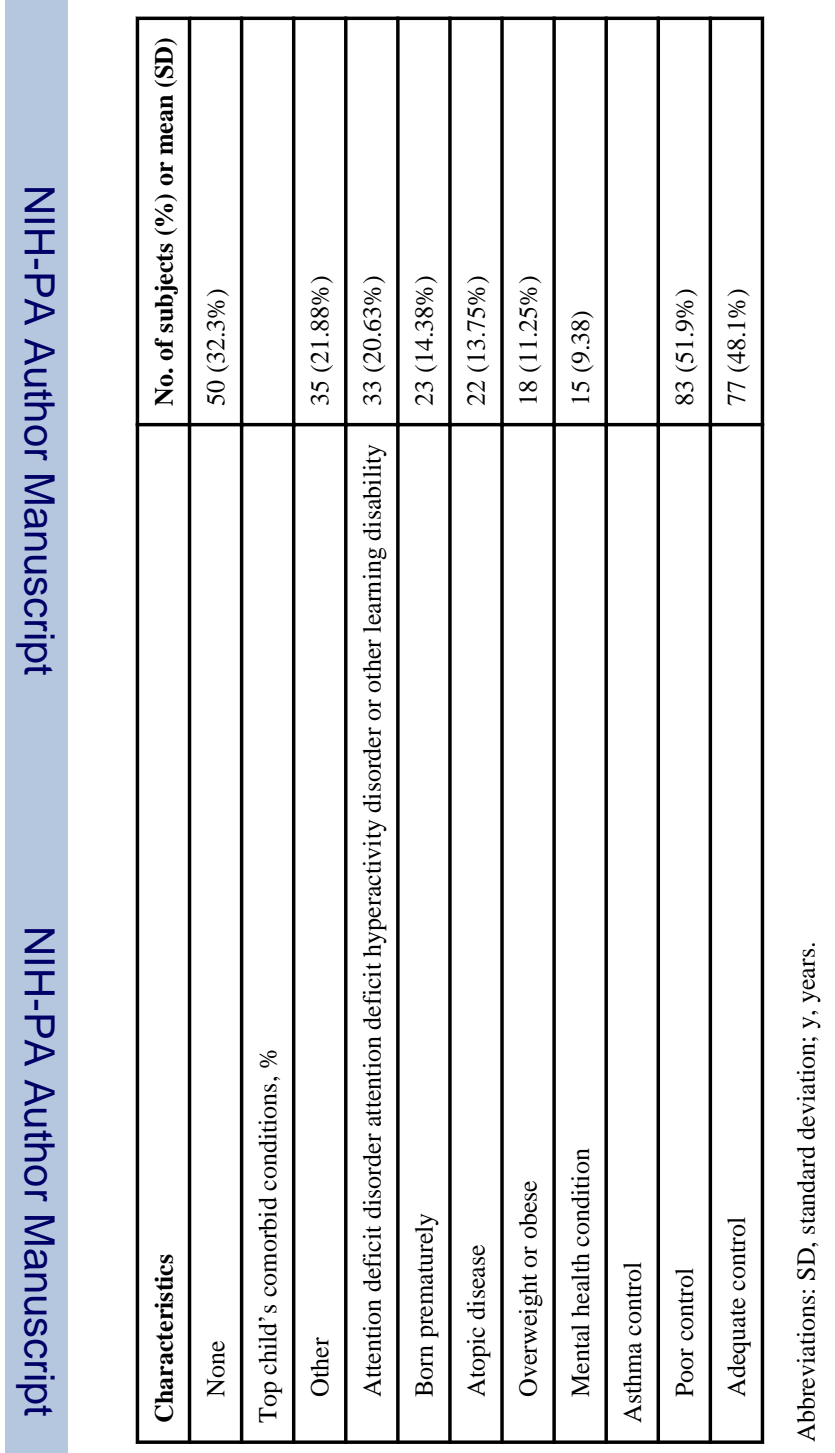

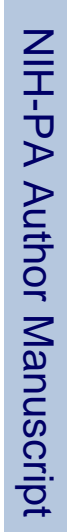




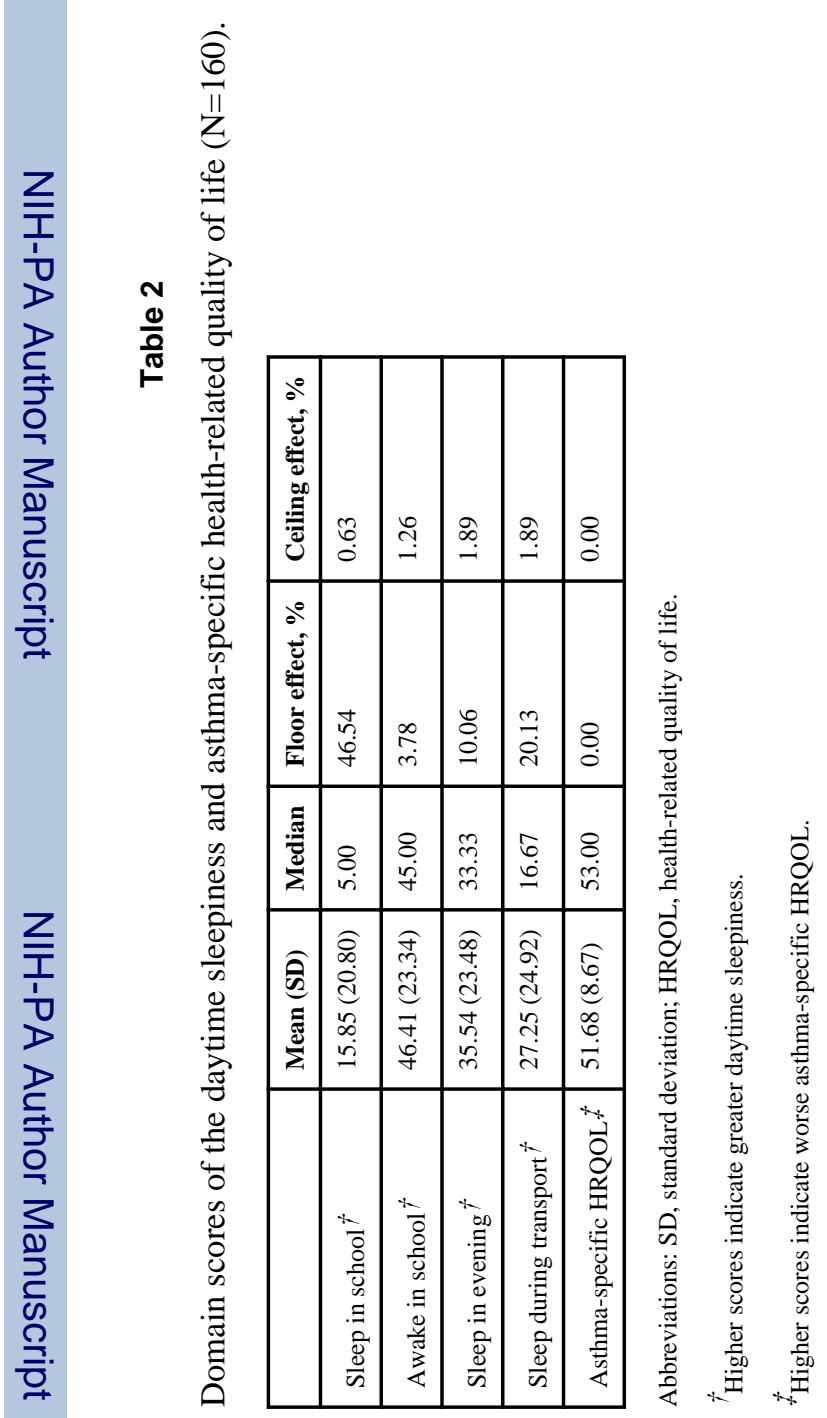

Sleep Med. Author manuscript; available in PMC 2014 July 01. 


\section{Table 3}

Bivariate analyses of asthma control with daytime sleepiness and with asthma-specific health-related quality of life.

\begin{tabular}{|c|c|c|c|c|}
\hline & Adequate control & Poor control & Difference & $t$ value \\
\hline Sleep in school ${ }^{\dagger}$ & 10.48 & 20.78 & -10.30 & $-3.25^{* *}$ \\
\hline Awake in school ${ }^{\dagger}$ & 43.87 & 48.73 & -4.87 & -1.32 \\
\hline Sleep in evening ${ }^{\dagger}$ & 27.86 & 40.65 & -12.79 & $-3.59^{* * *}$ \\
\hline Sleep during transport ${ }^{\dagger}$ & 19.30 & 34.53 & -15.23 & $-4.03^{* * * *}$ \\
\hline Asthma-specific HRQOL ${ }^{\neq}$ & 48.13 & 54.96 & -6.83 & $-5.41^{* * * *}$ \\
\hline
\end{tabular}

Abbreviation: HRQOL, health-related quality of life.

*** $P$ <.01.

**** $P<.001$

${ }^{\dagger}$ Higher scores indicate greater daytime sleepiness.

${ }^{*}$ Higher scores indicate worse asthma-specific HRQOL. 


\begin{tabular}{|c|c|c|c|c|c|c|c|c|c|c|c|c|c|c|c|}
\hline & 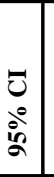 & $\begin{array}{l}n \\
0 \\
0 \\
8 \\
0 \\
0\end{array}$ & $\begin{array}{l}0 \\
0 \\
0 \\
0 \\
0 \\
i \\
i\end{array}$ & $\begin{array}{l}\text { I } \\
0 \\
\dot{0} \\
\dot{\theta}\end{array}$ & $\begin{array}{l}\hat{\bar{O}} \\
\dot{0} \\
\dot{0} \\
\dot{i}\end{array}$ & \begin{tabular}{|l}
$\hat{f}$ \\
0 \\
$\hat{c}$ \\
$\hat{i}$
\end{tabular} & \begin{tabular}{|l}
$\hat{y}$ \\
+ \\
$\vec{T}$ \\
$\vec{I}$ \\
\end{tabular} & $\mid \begin{array}{l}n \\
0 \\
0 \\
0 \\
i \\
i\end{array}$ & 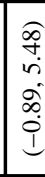 & $\mid$\begin{tabular}{|c}
$\hat{g}$ \\
$\dot{a}$ \\
$\vec{d}$ \\
$\hat{I}$ \\
\end{tabular} & 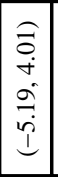 & 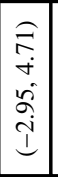 & & 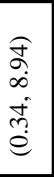 & $\begin{array}{l}5 \\
0 \\
0 \\
0 \\
0 \\
+1\end{array}$ \\
\hline & 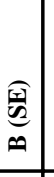 & $\begin{array}{l}{ }^{0} \\
0 \\
0 \\
0 \\
0 \\
0 \\
0\end{array}$ & $\begin{array}{l}\widehat{0} \\
\stackrel{0}{0} \\
\vdots \\
0 \\
0\end{array}$ & $\begin{array}{l}\hat{\sigma} \\
\stackrel{0}{0} \\
0 \\
0 \\
0\end{array}$ & \begin{tabular}{|l}
$\widehat{o}$ \\
$\stackrel{0}{0}$ \\
$\stackrel{0}{0}$ \\
0 \\
0
\end{tabular} & 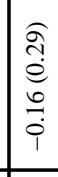 & 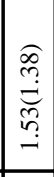 & 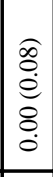 & & 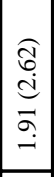 & \begin{tabular}{|c|c|}
0 \\
0 \\
0 \\
0 \\
0 \\
$i$ \\
\end{tabular} & 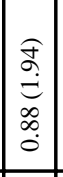 & 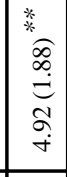 & 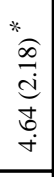 & 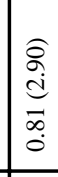 \\
\hline & $\begin{array}{l}z \\
0 \\
0 \\
0\end{array}$ & & & & $\begin{array}{l}\hat{G} \\
0 \\
+ \\
\dot{d}\end{array}$ & 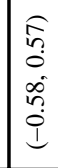 & $\mid \begin{array}{l}\hat{O} \\
\dot{\sigma} \\
\dot{f} \\
i \\
i \\
i\end{array}$ & \begin{tabular}{|l}
0 \\
0 \\
0 \\
$\underline{n}$ \\
$i$ \\
$i$
\end{tabular} & 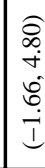 & 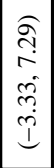 & $\mid \begin{array}{c}\widehat{\alpha} \\
\dot{0} \\
\dot{o} \\
\dot{y} \\
\dot{I} \\
\end{array}$ & 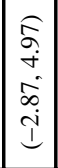 & & 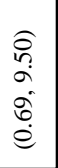 & \\
\hline
\end{tabular}

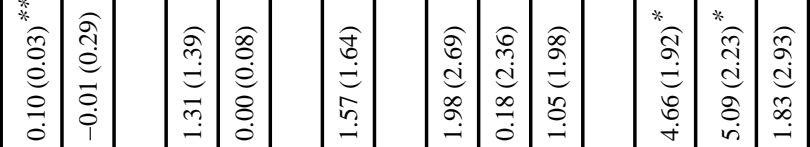

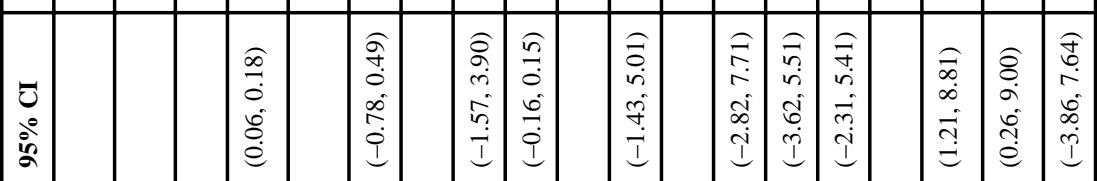

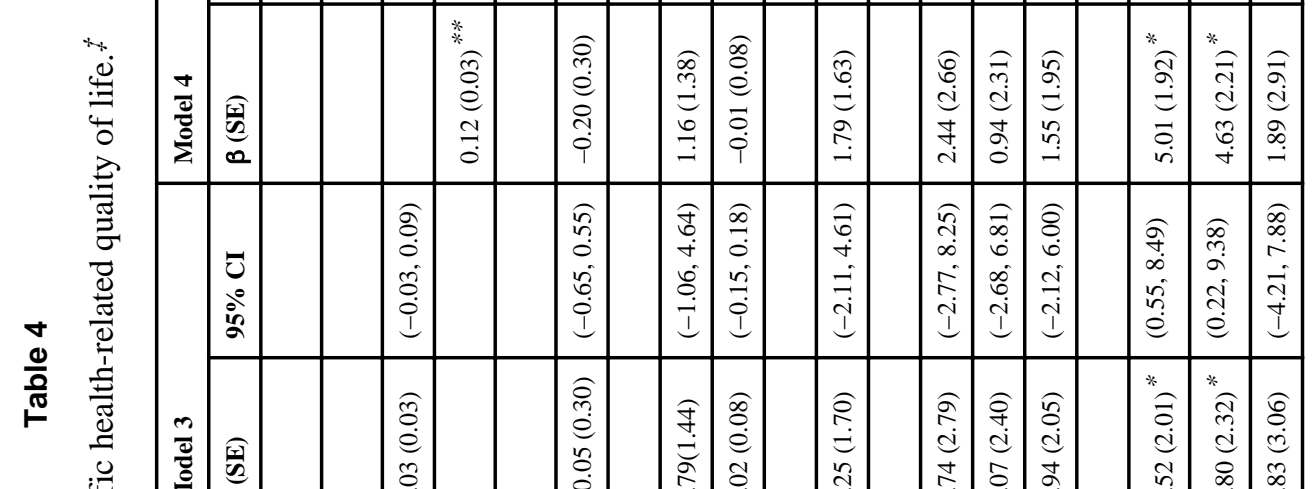


